\title{
Postsynaptic Density-93 Clusters Kv1 Channels at Axon Initial Segments Independently of Caspr2
}

\author{
Yasuhiro Ogawa, ${ }^{1}$ Ido Horresh, ${ }^{2}$ James S. Trimmer, ${ }^{3}$ David S. Bredt, ${ }^{4}$ Elior Peles, ${ }^{2}$ and Matthew N. Rasband ${ }^{1}$ \\ ${ }^{1}$ Department of Neuroscience, Baylor College of Medicine, Houston, Texas 77030, ${ }^{2}$ Department of Molecular Cell Biology, Weizmann Institute of Science, \\ Rehovot, Israel 76100, ${ }^{3}$ Section of Neurobiology, Physiology, and Behavior, College of Biological Sciences, University of California, Davis, Davis, California \\ 95616, and ${ }^{4}$ Department of Neuroscience, Eli Lilly and Company, Indianapolis, Indiana 46285
}

Postsynaptic density-93 (PSD-93)/Chapsyn-110 is a PDZ (PSD-95/Discs large/zona occludens-1) domain-containing membraneassociated guanylate kinase (MAGUK) that functions as a scaffold to assemble channels, receptors, and other signaling proteins at cell membranes. PSD-93 is highly enriched at synapses, but mice lacking this protein have no synaptic structural abnormalities, probably because of overlapping expression and redundancy with other MAGUKs. Consequently, the function of PSD-93 is not well understood. Here, we show that PSD-93, but not other MAGUKs, is enriched at the axon initial segment (AIS), where it colocalizes with Kv1.1, Kv1.2, $\mathrm{Kv1.4}$, and $\mathrm{Kv} \beta 2$ subunit-containing $\mathrm{K}^{+}$channels, Caspr2, and TAG-1 (transient axonal glycoprotein-1). When coexpressed with Kv1 channels in heterologous cells, PSD-93 induces formation of large cell-surface clusters. Knockdown of PSD-93 in cultured hippocampal neurons by RNA interference disrupted Kv1 channel localization at the AIS. Similarly, PSD-93-/- mice failed to cluster Kv1 channels at the AIS of cortical and hippocampal neurons. In contrast, Caspr2, which mediates Kv1 channel clustering at the juxtaparanode, is not required for localization of Kv1 channels at the AIS. These results show PSD-93 mediates AIS accumulation of Kv1 channels independently of Caspr2.

Key words: action potential; juxtaparanode; scaffold; ankyrin; cell adhesion molecule; MAGUK

\section{Introduction}

Ion channels are enriched in neurons at the axon initial segment (AIS) and node of Ranvier, where they generate, modulate, and propagate action potentials (Lai and Jan, 2006). Proper neuronal function requires that specific types of ion channels are restricted to discrete membrane domains. Voltage-gated sodium channels $\left(\mathrm{Na}_{\mathrm{v}}\right), \mathrm{KCNQ} 2 / 3 \mathrm{~K}^{+}$channels, neurofascin-186 (NF-186), ankyrinG (ankG), and $\beta I V$ spectrin are highly enriched at the AIS and nodes (Hedstrom and Rasband, 2006). In myelinated axons, cell adhesion molecules (CAMs) cluster scaffolds and ion channels (Poliak and Peles, 2003; Eshed et al., 2005; Sherman et al., 2005). AIS clustering of $\mathrm{Na}_{\mathrm{v}}$ and KCNQ2/3 channels depends on binding to the scaffolding protein ankG, because these channels are depleted from the AIS of neurons lacking ankG (Zhou et al., 1998; Garrido et al., 2003; Lemaillet et al., 2003; Pan et al., 2006). Whereas the CAMs NF-186 and NrCAM cluster ion channels at nodes of Ranvier, they are dispensable for ion channel clustering at the AIS (Dzhashiashvili et al., 2007; Hedstrom et al., 2007).

Recently, Kv1.2 channels were reported at the AIS of human cortical pyramidal neurons (Inda et al., 2006), rat retinal ganglion

Received Sept. 27, 2007; revised Feb. 14, 2008; accepted Feb. 14, 2008.

This work was supported by the Dr. Miriam and Sheldon G. Adelson Medical Research Foundation, National Institutes of Health Grants NS044916 (M.N.R.) and NS034383 (J.S.T.), and by the National Multiple Sclerosis Society (E.P.).Y.O. was supported by a postdoctoral fellowship from the National Multiple Sclerosis Society. M.N.R. is a Harry Weaver Neuroscience Scholar of the National Multiple Sclerosis Society.

Correspondence should be addressed to Dr. Matthew N. Rasband, Department of Neuroscience, Baylor College of Medicine, One Baylor Plaza, Houston, TX 77030. E-mail: Rasband@bcm.edu.

DOI:10.1523/JNEUROSCI.4431-07.2008

Copyright @ 2008 Society for Neuroscience $\quad$ 0270-6474/08/285731-09\$15.00/0 cells (Van Wart et al., 2007), and avian nucleus laminaris neurons (Kuba et al., 2006). AIS Kv1.2 is more spatially restricted than ankG and is only in the distal segment of the AIS, suggesting ankG is not the sole determinant of Kvl channel clustering (Van Wart et al., 2007). In myelinated axons, Kv1 channels flank nodes and are sequestered beneath the myelin sheath in juxtaparanodal membrane domains (Rasband, 2004). There, an axonal heterodimer consisting of the CAMs Caspr2 and transient axonal glycoprotein-1 (TAG-1) participate in trans-interactions with glial TAG-1. These proteins are required for Kv1 channel localization (Poliak et al., 2003; Traka et al., 2003). Because Caspr2 and Kv1 channels both have PDZ [postsynaptic density-95 (PSD95)/Discs large/zona occludens-1] binding motifs, they may be linked by a PDZ-domain scaffolding protein (Poliak et al., 1999). Indeed, PSD-95 localizes to juxtaparanodes and coimmunoprecipitates with Kv1 channels. However, mice lacking PSD-95 have normal juxtaparanodal Caspr2 and Kv1 channels (Rasband et al., 2002). Intriguingly, Caspr2 occurs at the AIS of human pyramidal neurons (Inda et al., 2006).

Here, we report a macromolecular protein complex at the AIS composed of Kv1 channels, Caspr2, TAG-1, and the PDZdomain containing scaffolding protein PSD-93/Chapsyn-110. We show that PSD-93 is necessary for Kv1 channel clustering at the AIS. However, in contrast to the juxtaparanode, Caspr2 is not required for localization of $\mathrm{Kv} 1$ channels to the AIS. Our results demonstrate that AIS and juxtaparanodal membrane domains share many common components, yet have distinct mechanisms that underlie their formation and maintenance. 


\section{Materials and Methods}

Animals. Sprague Dawley rats were purchased from Charles River. Caspr2-/ - and PSD-93-/- mice have been described previously (McGee et al., 2001; Poliak et al., 2003). Animals were housed at the Center for Laboratory Animal Care at the University of Connecticut Health Center and at the Weizmann Institute of Science. All experiments were performed in accordance with the National Institutes of Health guidelines for the humane treatment of animals.

Antibodies. Antibodies against $\mathrm{Kv}$ channel subunits and the pan- $\mathrm{Na}_{\mathrm{v}}$ channel antibody have been described previously (Rhodes et al., 1995; Bekele-Arcuri et al., 1996; Rasband et al., 1999; Tiffany et al., 2000). Mouse monoclonal anti-PSD-93 (N18/30) and polyclonal anti-PSD-93 antibodies were obtained from NeuroMab and from Alomone Labs, respectively. Additional rabbit polyclonal anti-PSD-95 and rabbit polyclonal anti-PSD-93 antibodies were kindly provided by Dr. Masahiko Watanabe (Hokkaido University, Sapporo, Japan) (Fukaya and Watanabe, 2000). The mouse monoclonal anti-PSD-95 (K28/43.2) has been described previously (Rasband et al., 2002). Rabbit anti- $\beta$ IV spectrin"specific" domain antibodies have been described previously (Berghs et al., 2000). Mouse monoclonal ankG antibodies were purchased from Invitrogen. Rabbit polyclonal anti-Caspr2 antibody was purchased from United States Biological. Chicken polyclonal anti-microtubuleassociated protein 2 (MAP2) antibody was purchased from EnCor Biotechnology. Rabbit polyclonal antibodies against proteins $4.1 \mathrm{G}$ and $4.1 \mathrm{~N}$ were kindly provided by Dr. Ilya Bezprozvanny (University of Texas Southwestern, Dallas, TX). The rabbit polyclonal antibodies against protein $4.1 \mathrm{~B}$ have been described previously (Gollan et al., 2002). Secondary antibodies used were Alexa-594-conjugated goat anti-mouse, Alexa-488conjugated goat anti-rabbit (Invitrogen), and 7-amino-4methylcoumarin-3-acetic acid (AMCA)-conjugated goat anti-chicken (Jackson ImmunoResearch).

Hippocampal neuron culture. Pregnant rats [embryonic day 16 (E16) to E18] were deeply anesthetized with halothane. Embryos were removed under sterile conditions, and brains were collected into ice-cold HBSS (Invitrogen). Embryonic hippocampi were then dissected and collected in HBSS. These hippocampi were incubated with $0.25 \%$ trypsin in HBSS at $37^{\circ} \mathrm{C}$ for $15 \mathrm{~min}$ and washed with HBSS. After adding plating media [Neurobasal medium (Invitrogen) supplemented with 10\% FCS], these hippocampi were triturated gently using a fire-polished Pasteur pipette. The cell suspension was left for $5 \mathrm{~min}$, and the supernatant was collected into a new tube to remove debris. Cells were then plated on cover glass coated with $1 \mathrm{mg} / \mathrm{ml}$ poly-D-lysine and $20 \mu \mathrm{g} / \mathrm{ml} \mathrm{laminin}$ at $2.5-3 \times 10^{5}$ cells $/ 35 \mathrm{~mm}$ dish. Neurons were incubated in a humidified $5 \% \mathrm{CO}_{2}$ incubator at $37^{\circ} \mathrm{C}$. The media was exchanged to maintenance media [Neurobasal medium with 2\% B27 (Invitrogen), $0.5 \mathrm{~mm}$ L-glutamine, and $25 \mu \mathrm{M}$ L-glutamate] after $2-4 \mathrm{~h}$. On day $3,1 \mu \mathrm{M}$ cytosine arabinoside (Sigma) was added into culture media to inhibit proliferating cell growth. The cultures were maintained by exchanging half of the volume of media twice a week with new maintenance media.

Short-hairpin RNA and transfection. For expression of short-hairpin RNA (shRNA), we subcloned into pBlueScriptII KS - (Stratagene), a human $\mathrm{H} 1$ promoter derived from pSuper and 64-Mer oligonucleotides containing the sense and antisense of the target sequence linked by a hairpin loop of nine bases (TTCAAGAGA) and an added termination signal (TTTTT). The sequence of the sense strand of 19 nucleotides was chosen to target rat PSD-93 (RNU49049). Control shRNA: 5'-GCAUGUCACGAUGUUACAA-3'; r1 shRNA (bases 1159-1177): 5' -CACUCUUAUUCUCCACCAA-3'; and r3 shRNA (bases 2771-2789): 5'-GCAAGCUUGUUAUUGAAGA-3'. Hippocampal neurons were transiently cotransfected at $10-11 \mathrm{~d}$ after plating using Lipofectamine 2000 (Invitrogen) to deliver an elongation factor $1 \alpha(\mathrm{EF} 1 \alpha)$ promoter driven green fluorescent protein (GFP) expression vector for identification of transfected neurons and the human $\mathrm{H} 1$ promoter driven shRNA expression vectors. Briefly, culture medium was removed until $1 \mathrm{ml}$ remained in the $35 \mathrm{~mm}$ dish. GFP plasmid $(0.5 \mu \mathrm{g})$ and pSUPER $(1 \mu \mathrm{g})$ were mixed in $200 \mu \mathrm{l}$ of Neurobasal medium with $5 \mu \mathrm{l}$ of Lipofectamine 2000. This mixture was added to each $35 \mathrm{~mm}$ dish and incubated at $37^{\circ} \mathrm{C}$ for $4 \mathrm{~h}$ before exchanging culture medium. Transfected neurons were analyzed $10 \mathrm{~d}$ later. For the clustering assay, recombinant plasmids were cotransfected into COS7 cells using lipofectamine 2000 according to the instructions of the manufacturer. The following plasmids were used: pGW-PSD-93EGFP (a gift from Dr. Bonnie Firestein, Rutgers, Piscataway, NJ), pGW-PSD95 (a gift from Dr. Morgan Sheng, The Picower Institute, Cambridge, MA), RBG4-Kv1.1, RBG4-Kv1.2, RBG4-Kv1.4 (Nakahira et al., 1996), and p3XFLAG-Caspr2 (amino acids 1078-1332). Transfected cells were analyzed $18-24 \mathrm{~h}$ after transfection by immunocytochemistry.

Immunostaining. Neurons were fixed with $1 \%$ paraformaldehyde (PFA) in PBS for $15 \mathrm{~min}$ at $4^{\circ} \mathrm{C}$. Brains were fixed by immersion with $4 \%$ PFA for $30 \mathrm{~min}$ at $4^{\circ} \mathrm{C}$, cryoprotected with $20 \%$ sucrose, embedded in Tissue-Tek (Miles) OCT mounting medium, and frozen on dry ice powder. Blocks were cut using a cryostat (Leica) to obtain $20-\mu$ m-thick sections, and the sections were placed on precoated slides (Thermo Fisher Scientific). Cultured neurons or brain sections were blocked with $4 \%$ nonfat dry milk powder in TBS (10 mM Tris- $\mathrm{HCl}, \mathrm{pH} 7.5,0.15 \mathrm{M} \mathrm{NaCl})$ with $0.3 \%$ Triton X-100 for $30 \mathrm{~min}$ at room temperature. Primary antibodies diluted in the blocking buffer were added at appropriate concentrations, incubated at room temperature overnight, and washed with PBS. Secondary antibodies were incubated at room temperature for $1 \mathrm{~h}$ and washed with PBS. Fluorescence images were acquired using a Zeiss Axioskop 2 fluorescence microscope fitted with a Hamamatsu ORCA-ER camera.

Statistical analysis. The Mann-Whitney $U$ test was used to determine relationships between control shRNA and PSD-93 targeted shRNA transfected neurons, which were calculated using StatView for Mac. All percentages given are median values for each measurement.

\section{Results \\ Multiple Kv1 channel subunits are located at the axon initial segment}

The generation, modulation, and duration of axonal action potentials depend on both the high densities and the specific types of ion channels found at the AIS (Hedstrom and Rasband, 2006; Khaliq and Raman, 2006; Shu et al., 2007). Kv1 channels are prominent in axons and nerve terminals (Gu et al., 2003; Trimmer and Rhodes, 2004) and modulate action potentials (Kole et al., 2007). We used a panel of mouse monoclonal and rabbit polyclonal Kv1 channel subunit-specific antibodies to determine the molecular composition of the AIS Kv1 channels in cultured rat hippocampal neurons. We used antibodies against $\beta$ IV spectrin, $\mathrm{Na}_{\mathrm{v}}$ channels, and ankG to identify the AIS. Somatodendritic domains were defined by immunostaining with antibodies against MAP2. We found Kv1.1, Kv1.2, and Kv1.4 enriched the AIS (Fig. $1 A-C$ ) of neurons maintained for $11 \mathrm{~d}$ in vitro (DIV). We obtained identical results using Kv1 channel $\alpha$-subunitspecific antibodies from both rabbit and mouse (data not shown). Although Kv1.6 has been reported in mouse hippocampal cultures (Grosse et al., 2000), we were unable to detect any specific immunoreactivity (data not shown). We also found $\mathrm{Kv} \beta$ subunits enriched at the AIS of many cultured hippocampal neurons (Fig. 1D) (Fig. S1 A, available at www.jneurosci.org as supplemental material). These same Kv1 channel $\alpha$-subunits were also detected at the AIS of postnatal day 10 (P10) cortical neurons in vivo (Fig. 2). Therefore, Kv1.1, Kv1.2, and Kv1.4 $\alpha$-subunitcontaining Kv channels are enriched at the AIS in vitro and in vivo where they likely exist as heteromultimeric complexes together with $\mathrm{Kv} \beta$ subunits.

\section{PSD-93 colocalizes with Kv1 channels at the AIS in vivo and in vitro}

Localization and retention of $\mathrm{Na}_{\mathrm{v}}$ and $\mathrm{KCNQ} 2 / 3 \mathrm{Kv}$ channels at the AIS depends on a common intracellular domain that mediates channel interaction with the AIS scaffolding protein ankG 


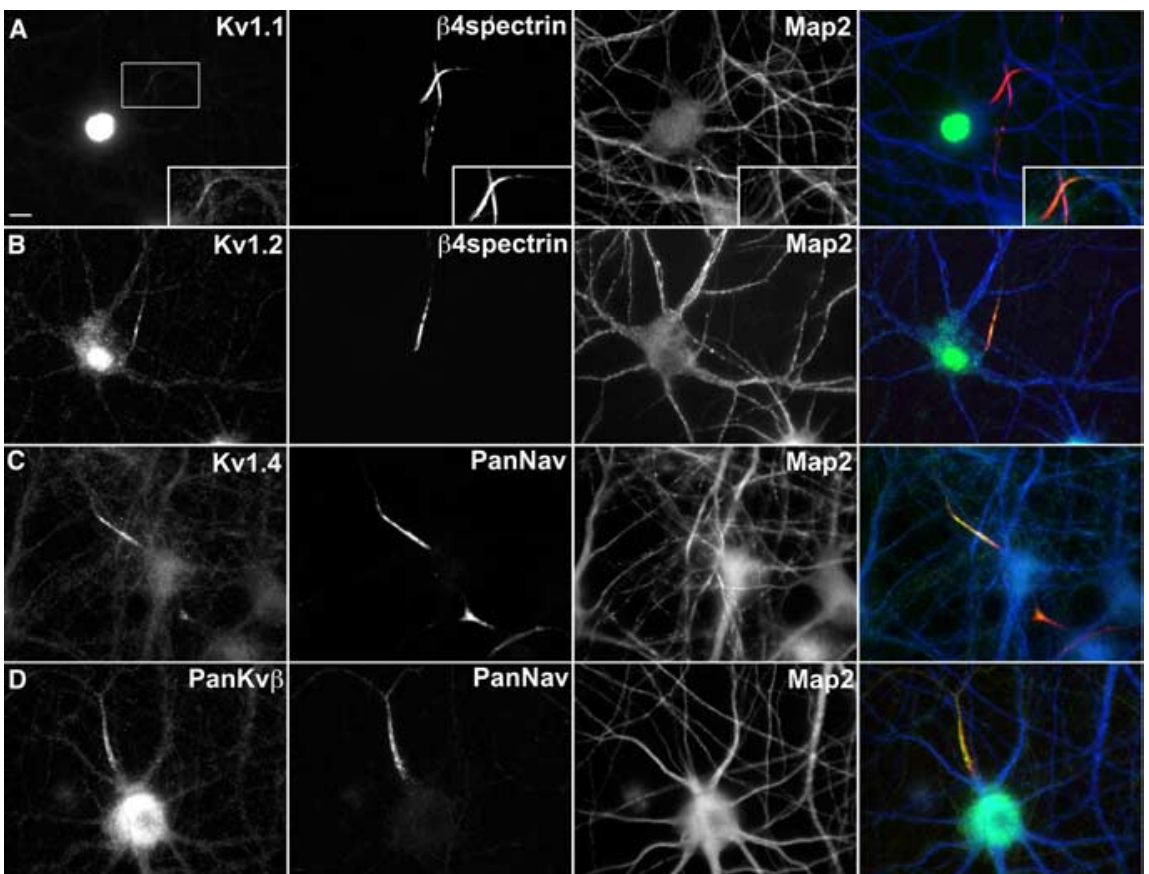

Figure 1. Kv1 channel $\alpha$-subunits and $\beta$-subunits are enriched at the AIS in cultured hippocampal neurons. Kv1.1 (A), Kv1.2 $(\boldsymbol{B})$, Kv1.4 (C), and $\mathrm{Kv} \beta(\boldsymbol{D})$ subunits (green) are located at the AIS, where they colocalize with $\beta \mathrm{IV}$ spectrin or $\mathrm{Na}_{\mathrm{v}}$ channels (red). Somatodendritic domains are defined by MAP2 immunoreactivity (blue). Scale bar, $10 \mu \mathrm{m}$.

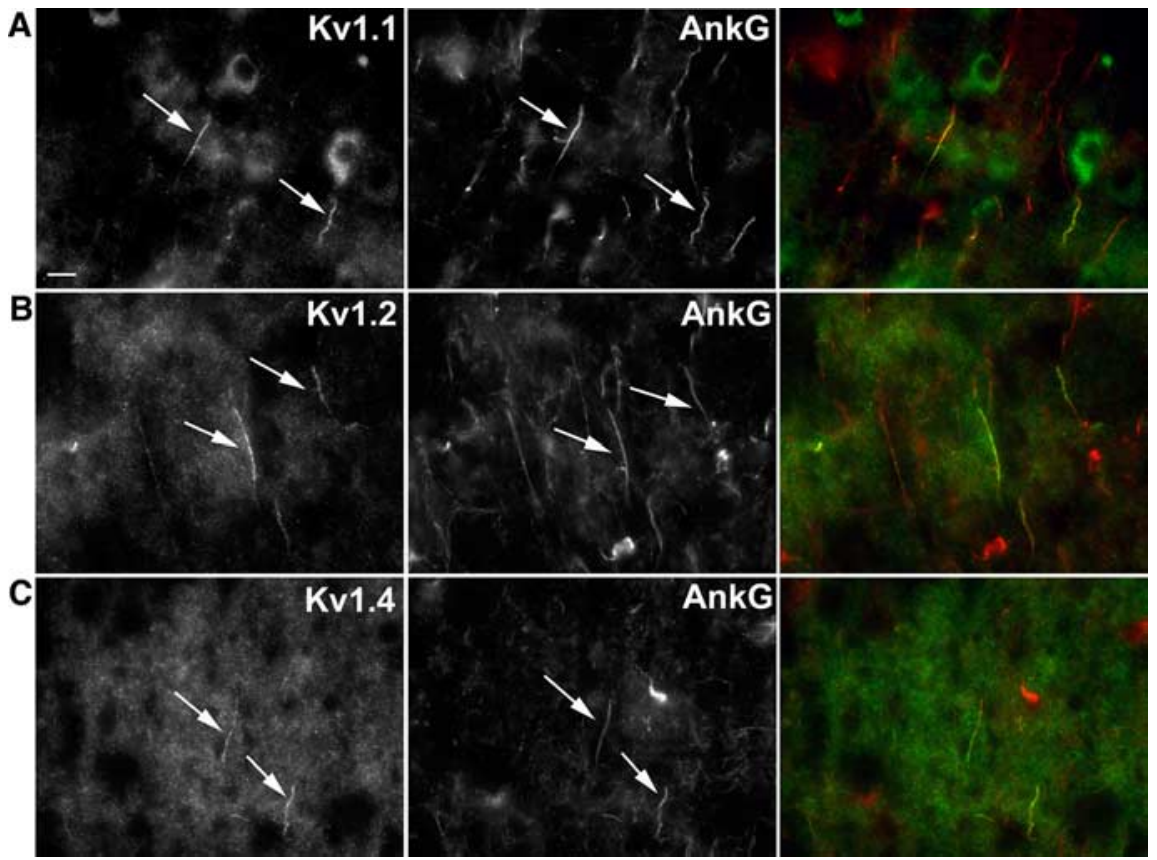

Figure 2. Kv1 channel $\alpha$-subunits are enriched at the AIS of P10 rat cortical neurons. Kv1.1 (A), Kv1.2 (B), and Kv1.4 (C) $\alpha$-subunits (green) colocalize with ankG (red) at the AIS (arrows). Scale bar, $10 \mu \mathrm{m}$.

(Garrido et al., 2003; Pan et al., 2006). How are Kv1 channels clustered at the AIS? Does their localization also depend on ankG or on some other scaffolding protein? Kv1.1, Kv1.2, and Kv1.4 each contain a consensus class I C-terminal PDZ binding motif $(\mathrm{xS} / \mathrm{TxV})$ but not the ankG binding motif present in $\mathrm{Na}_{\mathrm{v}}$ and KCNQ channel subunits (Garrido et al., 2003; Lemaillet et al., 2003; Pan et al., 2006). PDZ binding motifs permit the interaction of Kv1 channels with PSD-95, a prominent scaffolding protein found at synapses (Kim et al., 1995). PSD-95 is the prototyp- ical member of a family of membraneassociated guanylate kinases (MAGUKs) or synaptic-associated proteins (SAPs) that include SAP97, PSD-95/SAP90, SAP102, and PSD-93/Chapsyn-110. These proteins are structurally similar with three PDZ domains, an src homology domain, and a guanylate kinase (GK) domain (Sheng and Sala, 2001). Furthermore, MAGUKs colocalize and interact with Kv1 channels at other CNS locations, including cerebellar pinceau (Kim et al., 1995; Laube et al., 1996) and juxtaparanodes of myelinated axons (Rasband et al., 2002). Therefore, we asked whether these proteins might regulate the localization of Kv1 channels at the AIS.

Immunostaining of 11 DIV cultured hippocampal neurons revealed PSD-93 signals at synapses (Fig. 3A). In addition, PSD-93 immunoreactivity was detected at the AIS, where it colocalized with $\mathrm{Na}_{\mathrm{v}}$ channels (Fig. $3 A$, inset). In contrast, PSD-95 was detected only at synaptic sites and not at the AIS (Fig. $3 B$ ). Double-immunostaining with antibodies against PSD-93 and PSD-95 revealed only PSD-93 signals at the AIS (Fig. 3C, inset), and double-immunostaining with antibodies against Kv1.2 and PSD-93 showed that these two proteins colocalized at the AIS (Fig. 3D). These observations in vitro agree with a previous report of PSD-93 at the AIS (Rao et al., 1998). Despite a recent report that SAP102 interacts with $\mathrm{NrCAM}$, a CAM that is highly enriched at the AIS (Davey et al., 2005), we detected neither SAP102 nor SAP97 at the AIS (Fig. 3, $E$ and $F$, respectively). We also confirmed that PSD-93 is located at the AIS of $\mathrm{P} 10$ rat cortical neurons in vivo and that it colocalizes with ankG (Fig. $4 A$, arrows) and Kv1.2 (Fig. 4B, arrows).

PSD-93 and Kv1 channels make surface clusters in vitro

To demonstrate that Kv1 channels and PSD-93 interact, we performed a surfaceclustering assay by coexpressing Kv1 channels and PSD-95 or PSD-93 in COS7 cells (Kim et al., 1995, 1996; Tiffany et al., 2000). We used an anti-Kv1.1 antibody directed against an extracellular domain (Kv1.1ext) to detect surface Kv1.1 before permeabilizing the cells (Tiffany et al., 2000). Because the $\alpha$-subunit composition of Kv1 channels dramatically influences their surface expression (Manganas and Trimmer, 2000), we cotransfected Kv1.1 subunits together with Kv1.2 or Kv1.4. For example, Kv1.1 transfected alone localizes poorly to the cell surface (Fig. $5 A$ ), but after coexpression with Kv1.2 or Kv1.4, Kv1.1 can be detected uniformly at the cell surface using Kv1.1ext antibodies (Fig. 5B,C). As for Kv1 channels, expression of PSD-95 or PSD-93 alone revealed a uniform distribution throughout the cell without any apparent clustering (Fig. 5D,E). However, as shown previously (Manganas et al., 
2001), after coexpression of PSD-95 with Kv1.1/Kv1.2 (Fig. 5F) or Kv1.1/Kv1.4 (Fig. $5 G)$, the proteins redistributed into clearly defined surface clusters. Similarly, coexpression of PSD-93 with Kv1.1/Kv1.2 (Fig. $5 H$ ) or Kv1.1/Kv1.4 (Fig. 5I) also resulted in the formation of large surface clusters comprised of Kvl channel subunits and PSD-93. Therefore, as with the MAGUKs PSD-95 and SAP97 (Kim and Sheng, 1996), PSD-93 can interact with and cluster Kvl channels at the cell surface.

\section{PSD-93 is required for Kv1 channel localization at the AIS}

Is PSD-93 required for clustering of $\mathrm{Kv} 1$ channels at the AIS? To answer this question, we prepared $\mathrm{H} 1$ promoter driven shRNA plasmids to silence expression of PSD-93 in cultured hippocampal neurons. We confirmed the efficacy of gene silencing by coexpressing PSD-93-enhanced GFP (EGFP) and PSD-93 shRNA plasmids in COS7 cells (data not shown). We found two functional shRNA plasmids (R1 and R3; see Materials and Methods for details) that targeted different sequences in PSD-93 and that dramatically reduced the amount of PSD-93-EGFP expressed in the transfected COS7 cells. We then cotransfected R1, R3, or a control shRNA expression plasmid together with an EGFP expression plasmid (to identify transfected neurons) into cultured rat hippocampal neurons. In the control shRNA transfected hippocampal neurons, PSD-93 was detected at the AIS of $49.4 \%$ ( $n=7$; transfected cell number, 510) of EGFP + neurons (Fig. $6 \mathrm{~A}$, arrowhead, $C)$. However, only $7.3 \%(n=6$; transfected cell number, 521) and $1.6 \%$ ( $n=6$; transfected cell number, 474) of EGFP+ cells had detectable endogenous AIS PSD-93 when transfected with the R1 and R3 shRNA expression plasmids, respectively [R3 (Fig. 6A, arrowhead, $C$ ) and R1 (Fig. S1 $B$, available at www.jneurosci.org as supplemental material)]. Nontransfected cells in the same culture dish had normal PSD-93 at the AIS (Fig. 6A, arrow).

We next determined whether knockdown of PSD-93 expression affects Kv1 channel localization at the AIS. When transfected with the control shRNA, we found that $43.5 \%(n=5$; transfected cell number, 603) of EGFP + neurons had Kv1.4 immunoreactivity at the AIS (Fig. 6B, arrowhead, $C$ ). The AIS Kv1.4 signal intensity of control shRNA transfected neurons was similar to that in nontransfected cells (Fig. 6B, arrow). In contrast, fewer neurons transfected with the R1 or R3 shRNAs had Kv1.4 immunoreactivity at the AIS. Only $24.9 \%(n=6$; transfected cell number, $579)$ and $20.0 \%$ ( $n=6$; transfected cell number, 531) of EGFP+ neurons had detectable Kv1.4 at the AIS when transfected with the R1 and R3 shRNA expression constructs, respectively [R3 (Fig. 6B, arrowhead, C), R1 (Fig. S1B, available at www. jneurosci.org as supplemental material)], and similar results were observed for Kv1.1 (Fig. S1C, available at www.jneurosci.org as supplemental material). Because a few neurons still had weakly detect-
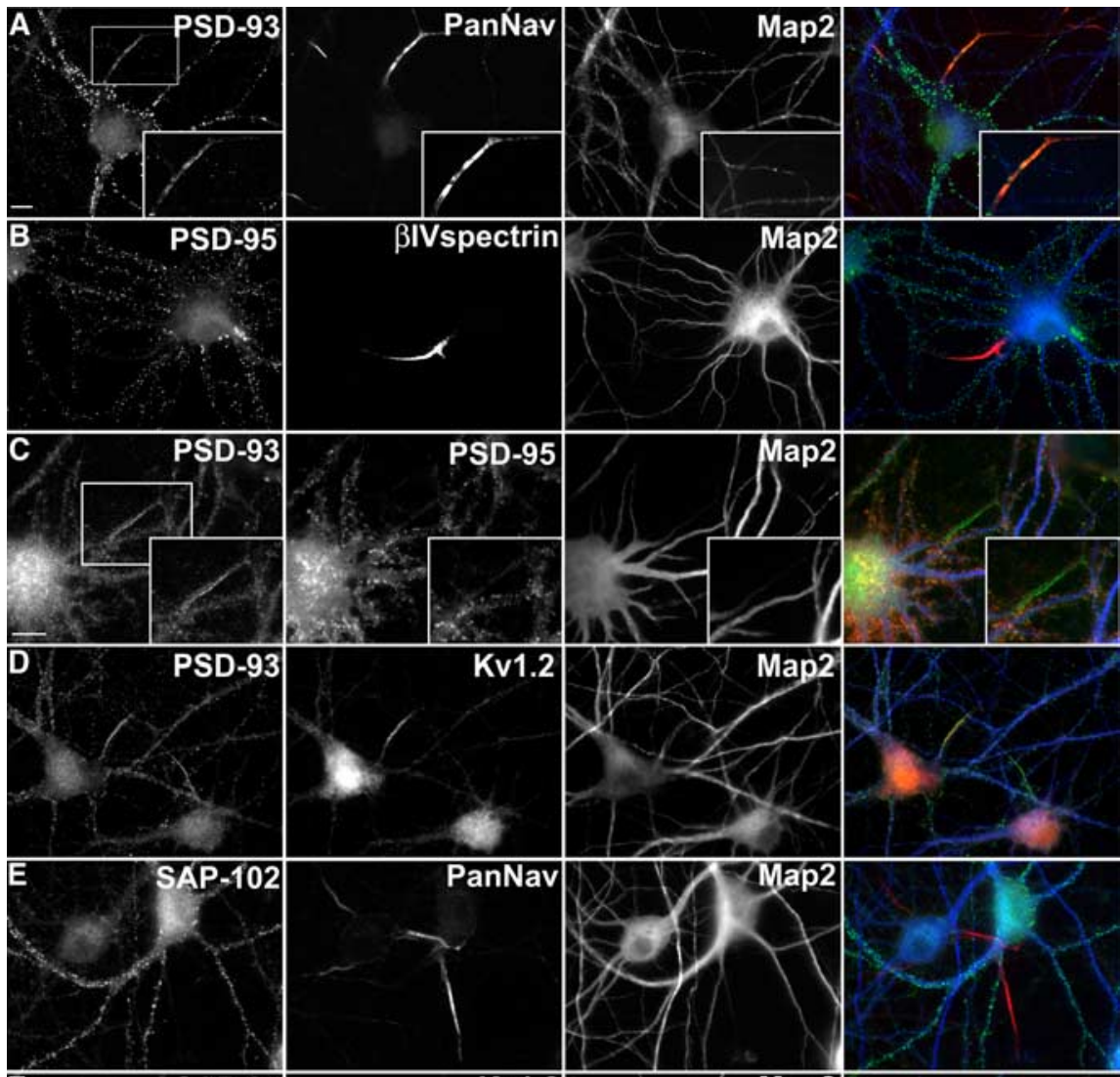

Figure 3. PSD-93, but not PSD-95, is enriched at the AIS of cultured hippocampal neurons. A, PSD-93 (green) is located at along dendrites but do not colocalize with $\mathrm{Na}_{\mathrm{v}}$ channels (red) at the AIS. Somatodendritic domains are defined by MAP2 immunostaining (blue). Scale bars, $10 \mu \mathrm{m}$.
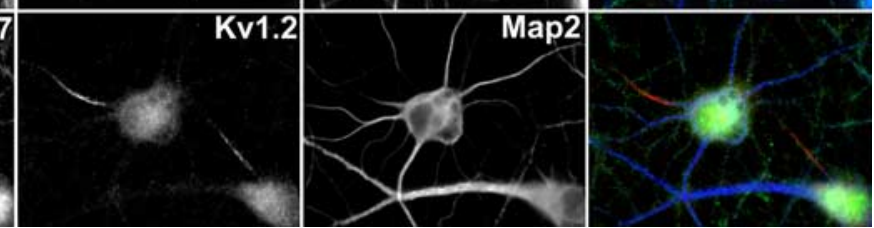

able Kv1.4 immunoreactivity at the AIS, we determined whether other MAGUKs compensate for loss of PSD-93. However, we did not detect PSD-95, SAP102, or SAP97 at the AIS of neurons lacking PSD-93 (Fig. S2, available at www.jneurosci.org as supplemental material), suggesting the residual weak Kv1.4 immunoreactivity reflects incomplete knockdown of PSD-93 and differences between anti-PSD-93 and anti-Kv1.4 sensitivities.

We next analyzed PSD-93-/- mice to confirm the dependence of Kv1 channel AIS localization on its interaction with PSD-93. As with P10 rats, cortical neurons of wild-type (WT) P10 mice had abundant Kv1.2 channel immunoreactivity at distal segments of the AIS, where it colocalized with $\beta$ IV spectrin (Fig. $7 A$, arrow). In contrast, we never observed AIS Kv1.2 immunoreactivity in P10 PSD-93-/- mice (Fig. 7B, arrow). Therefore, PSD-93 is required for Kv1 channel localization at the AIS.

\section{Caspr2 and TAG-1 are located at the AIS}

Because Caspr2 and TAG-1 mediate clustering and localization of Kv1 channels at juxtaparanodes (Poliak et al., 1999; Poliak et al., 2003; Traka et al., 2003), we considered whether these CAMs 


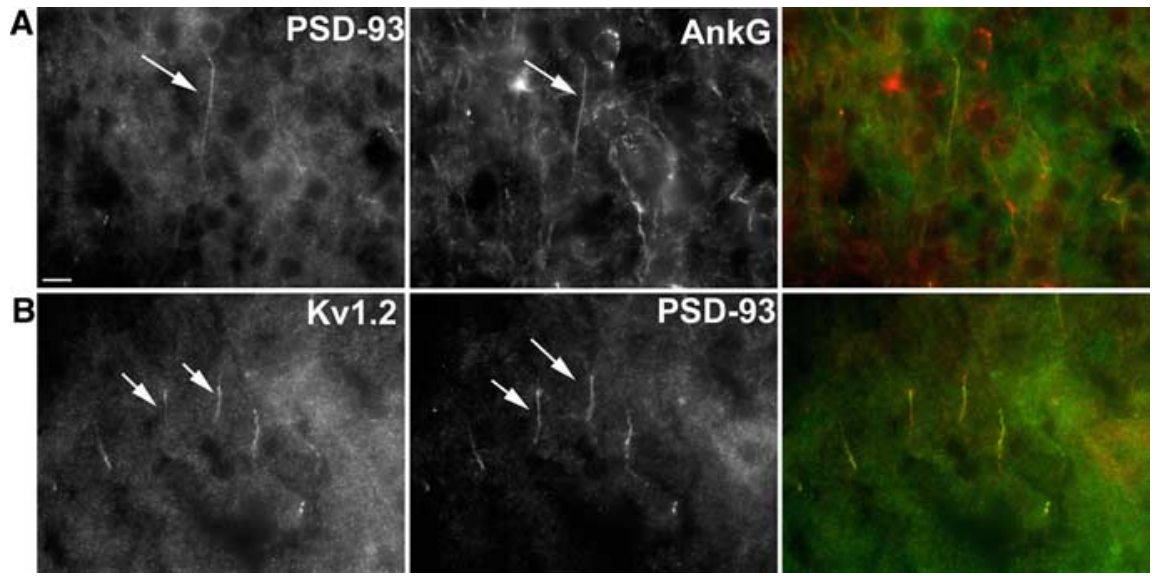

Figure 4. PSD-93 is enriched at the AIS of P10 rat cortical neurons. A, PSD-93 (green) colocalizes with ankG (red) immunostaining (arrows). B, Kv1.2 $\alpha$-subunits (green) colocalize with PSD-93 (red) at the AIS (arrows). Scale bar, $10 \mu \mathrm{m}$.

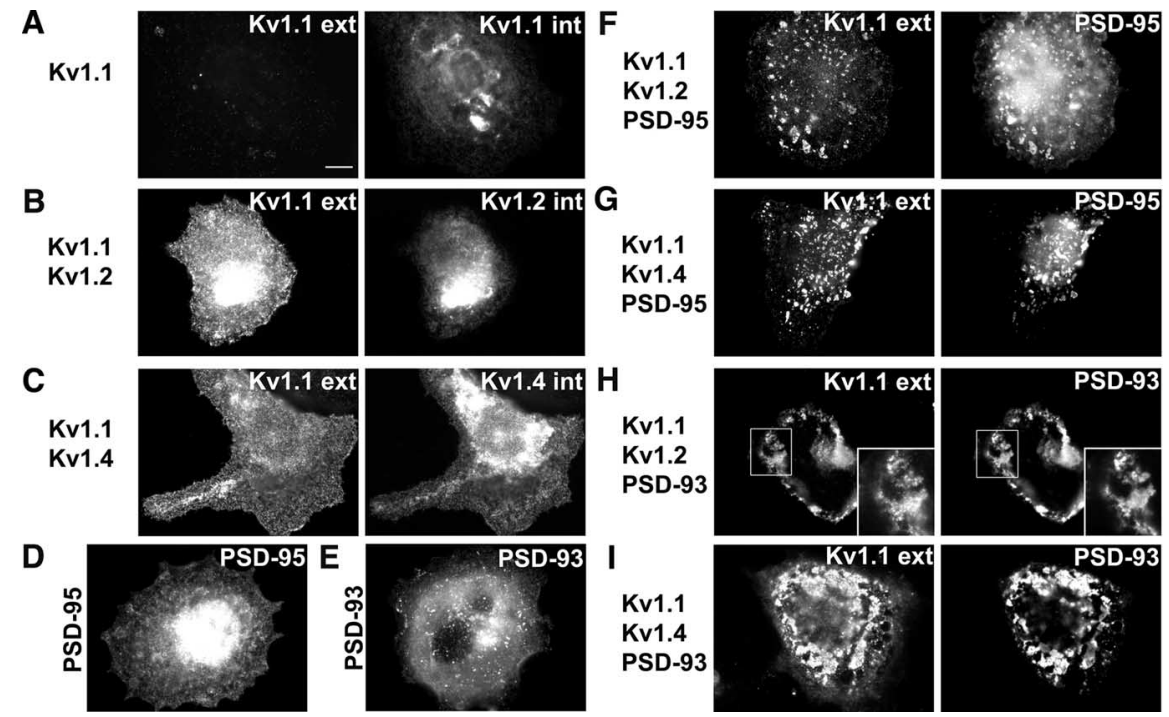

Figure 5. Coexpression of Kv1 channel $\alpha$-subunits with PSD-93 results in the formation of large surface clusters of Kv1 channels in COS7 cells. The CDNAs used in the transfections are listed to the left of each set of images. $\boldsymbol{A}$, Kv1.1 transfected cells labeled with antibodies against extracellular (Kv1.1ext) or intracellular (Kv1.1int) epitopes. B, C, Coexpression of Kv1.1 with Kv1.2 or Kv1.4 $\alpha$-subunits promotes the uniform surface expression of Kv1.1. D, E, PSD-95 or PSD-93 transfected COS7 cells reveal a uniform cytoplasmic staining for the introduced MAGUK. $\boldsymbol{F}, \boldsymbol{G}$, Coexpression of Kv1.1 with Kv1.2 $(\boldsymbol{F})$ or Kv1.4 (G) and PSD-95 results in the formation of large Kv1 channel surface clusters. Kv1.1 was detected using the Kv1.1ext antibody. $\boldsymbol{H}$, I, Coexpression of Kv1.1 with Kv1.2 $(\boldsymbol{H})$ or Kv1.4 (I) and PSD-93 results in the formation of large Kv1 channel surface clusters. Kv1.1 was detected using the Kv1.1ext antibody. Scale bar, $10 \mu \mathrm{m}$.

might also be located at the AIS. In rat hippocampal neuron cultures, we found Caspr2 and TAG-1 immunoreactivity at the AIS, and this immunoreactivity colocalized with $\mathrm{Na}_{\mathrm{v}}$ channels (Fig. 8A,C) and Kv1.2 (Fig. 8B). This observation agrees with a previous report by Inda et al. (2006), demonstrating Caspr2 at the AIS of human cortical neurons in vivo. Caspr 2 also interacts with protein 4.1B at juxtaparanodes (Poliak et al., 2001; DenisenkoNehrbass et al., 2003). However, we did not detect any enrichment of 4.1 proteins at the AIS (Fig. $8 D$ ) (Fig. S3, available at www.jneurosci.org as supplemental material).

Caspr 2 is not required for Kv1 channel localization at the AIS Is Caspr 2 required for Kv1 channel localization at the AIS? To answer this, we immunostained brains from Caspr2-/- and Caspr2+/- littermates. In both genotypes, we found Kv1.2 immunoreactivity that colocalized with $\beta I V$ spectrin at the AIS of hippocampal (Fig. 9, arrows) and cortical (data not shown) neurons. Therefore, Caspr2 is enriched at the AIS and interacts with Kv1 channels through PSD-93 but is not required for Kvl channel localization at the AIS.

\section{Discussion}

\section{Ion channels at the AIS}

Information processing in the nervous system depends on exquisitely regulated neuronal input and output. Neuronal input occurs in the form of synaptic transmission, and output occurs when these synaptic signals are integrated and depolarize the membrane sufficiently to elicit an action potential in the axon (Palmer and Stuart, 2006). The AIS functions as a physical bridge between the somatodendritic and axonal domains and as a master regulator linking information processing and transmission. Moreover, the excitability of the AIS depends on the types, density, and location of clustered ion channels. $\mathrm{Na}_{\mathrm{v}}$ channels initiate the action potential, and $\mathrm{Na}_{\mathrm{v}} 1.1, \mathrm{Na}_{\mathrm{v}} 1.2$, and $\mathrm{Na}_{\mathrm{v}} 1.6$ occur alone and in combinations at the AIS of different CNS neurons (Boiko et al., 2003; Garrido et al., 2003; Van Wart et al., 2007). KCNQ2 and KCNQ3 Kv channels are also enriched at the AIS in an ankG-dependent manner (Devaux et al., 2004; Pan et al., 2006). Mutations in KCNQ2 and KCNQ3 cause neonatal epilepsies, emphasizing their role in regulating neuronal excitability (Jentsch, 2000). In addition, Kv1.2 subunits occur at the AIS of diverse neurons (Inda et al., 2006; Kuba et al., 2006; Van Wart et al., 2007). Dodson et al. (2002) showed Kv1.1 and Kv1.2 subunits are enriched at the AIS of medial nucleus of the trapezoid body neurons and regulate action potential firing. We extend these results to show that in hippocampal and cortical neurons, Kv1.4 is also located at the AIS, where it likely forms heteromultimeric channels with $\mathrm{Kv1.1}, \mathrm{Kv1.2}$, and $\mathrm{Kv} \beta 2$. Kv1 channel subunits are capable of heteromultimerizing promiscuously, and the addition of Kv1.4 subunits in the channel would be expected to convert Kv1.1/ Kv1.2 subunit-containing channels from noninactivating delayed rectifiers to channels with transient A-type currents. Regulating the Kv1 channel subunit composition at the AIS may modulate excitable properties of the AIS. Kole et al. (2007) recently showed that Kv1 channels directly modulate the action potential waveform in the AIS of layer 5 pyramidal neurons, and that this facilitates transmitter release at intracortical synapses. These ideas are consistent with the observation that Kv1.1-/mice have seizures throughout life (Smart et al., 1998) and a subset of patients with long-term epilepsy have autoantibodies against Kv1 channels (Majoie et al., 2006). 
Mechanism of ion channel clustering at the AIS

$\mathrm{Na}_{\mathrm{v}}$ and $\mathrm{KCNQ} 2 / 3$ channel localization depends on direct binding to the scaffold ankG (Garrido et al., 2003; Pan et al., 2006). Some data suggested that ankG localization to the AIS depends on interaction with the cytoskeletal protein $\beta$ IV spectrin (Komada and Soriano, 2002). However, Yang et al. (2007) recently demonstrated that, like $\mathrm{Na}_{\mathrm{v}}$ and KCNQ2/3 channels, $\beta \mathrm{IV}$ spectrin localization to the AIS and nodes also depends on ankG, pointing to the central role of ankG in the molecular organization of these excitable domains (Hedstrom et al., 2007). The mechanisms that initiate ankG clustering at the AIS remain unknown.

As for $\mathrm{Na}_{\mathrm{v}}$ and $\mathrm{KCNQ} 2 / 3$ channels, $\mathrm{Kv} 1$ channel localization to the AIS depends on a scaffolding protein, albeit through binding to PSD-93 rather than binding to ankG. It is interesting to note that although other MAGUKs such as SAP102 appear to compensate for loss of PSD-93 from some synapses (Elias et al., 2006), this is not true at the AIS. Hence, PSD-93 has a highly specific function to cluster Kv1 channels at the AIS.

How does PSD-93 become localized to the AIS? One possibility is through its interaction with one of the three CAMs described previously at the AIS: NrCAM, NF186, and Caspr2. All three of these proteins have putative C-terminal PDZ binding motifs (-NSFV, -YSLA, and -EWLI, respectively) (Sheng and Sala, 2001), and $\mathrm{Nr}$ CAM, but not NF-186, binds to the MAGUK SAP102 (Davey et al., 2005). However, neither NF-186 nor NrCAM is recruited into large surface clusters when coexpressed with PSD-93 and Kv1 channels (Y. Ogawa and M. N. Rasband, unpublished results). Although Caspr2 is also found only at the distal AIS (Inda et al., 2006) and is required for Kv1 channel clustering at the juxtaparanode (Poliak et al., 2003; Traka et al., 2003), the results presented here show that Caspr2 is not required for Kv1 channel localization at the AIS, because Caspr2-null mice have Kv1 channels at the AIS.

Among all the AIS proteins identified previously, only Kv1 channels and $\mathrm{Na}_{\mathrm{v}} 1.6$ are restricted to the distal region of the AIS. In contrast, in some neurons, $\mathrm{Na}_{\mathrm{v}} 1.1$ is located in the proximal segment of the AIS (Ogiwara et al., 2007; Van Wart et al., 2007). This observation suggests that the different channel distributions between the proximal and distal AIS depend not only on ankG but on other mechanisms as well. Based on its distal AIS localization, Kv1 channel targeting may be related to the localization of $\mathrm{Na}_{\mathrm{v}} 1.6$ or its associated proteins. $\mathrm{Na}_{\mathrm{v}}$ channels consist of both a pore-forming $\alpha$ subunit and an accessory $\beta$ subunit. Four $\mathrm{Na}_{\mathrm{v}} \beta$ subunits have been identified and are members of the immunoglobulin superfamily of CAMs. Both $\mathrm{Na}_{\mathrm{v}} \beta 1$ and $\mathrm{Na}_{\mathrm{v}} \beta 3$ can interact with NF-186 and NrCAM (Ratcliffe et al., 2001), but these
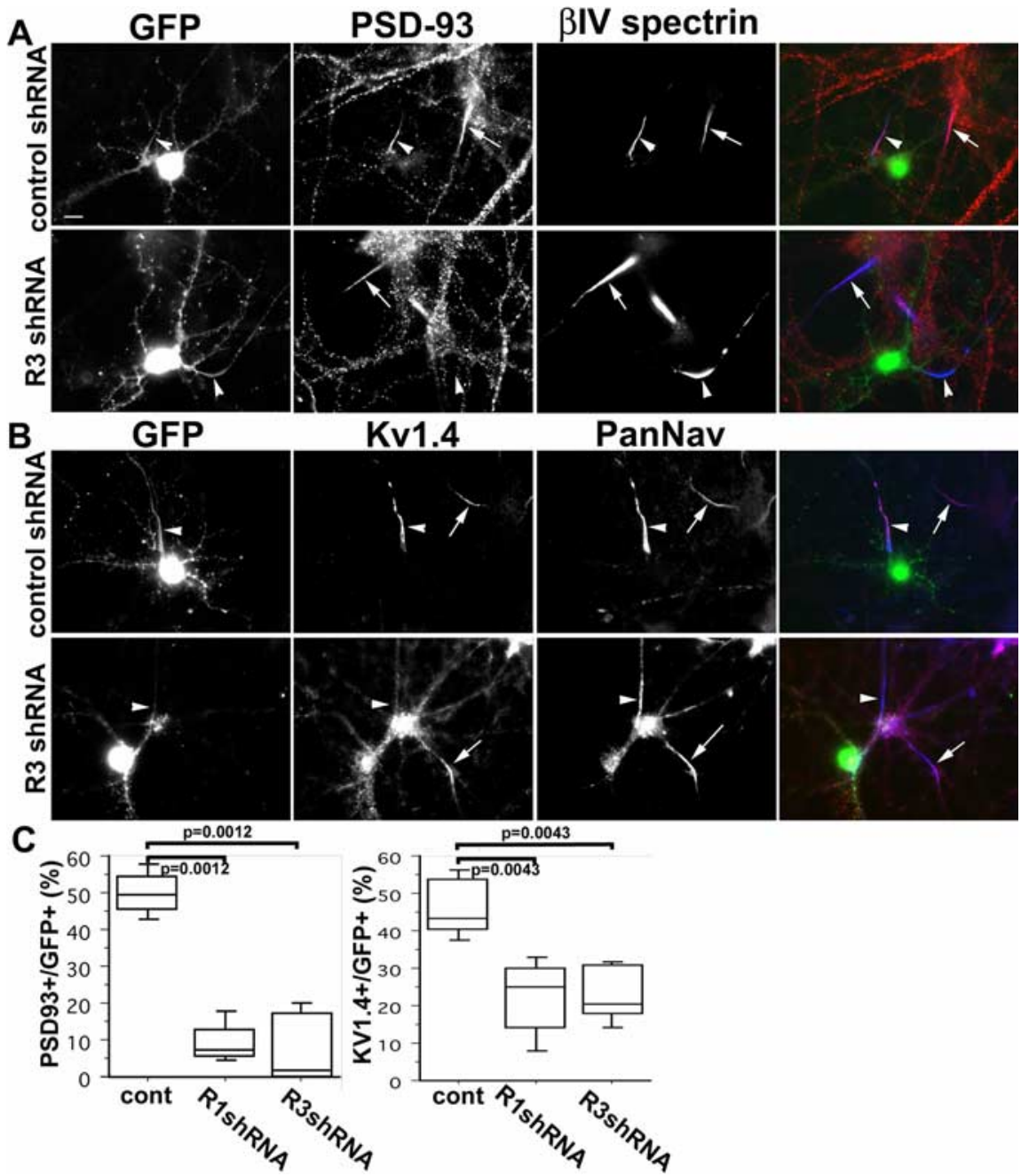

Figure 6. Silencing of PSD-93 by shRNA expression plasmids disrupts Kv1 channel clustering at the AIS. Cultured hippocampa neurons were transfected with shRNA expression vectors (R3) targeting PSD-93. Transfected neurons are identified by GFP signal. Untransfected neurons are indicated by arrowheads and arrows, respectively. Control shRNA expression plasmid transfected into can be detected in untransfected GFP - neurons. $B$ Transfection with R3 shRNA expression plasmids eliminates immunostaining for Kv1.4 at the AIS (arrowheads) of GFP + cells, but Kv1.4 immunoreactivity can be detected in untransfected GFP - neurons. Scale bar, $10 \mu \mathrm{m}$. C, Quantitative analysis for the number of GFP + cells with PSD-93 or Kv1.4 immunoreactivity at the AIS. Boxes, 75th percentile with the median indicated; bars, 10 th and 90 th percentiles. Analyzed using the Mann-Whitney $U$ test.

$\mathrm{Na}_{\mathrm{v}} \beta$ subunits do not interact with each other (McEwen and Isom, 2004). It is possible that the distinct channel distributions of $\mathrm{Na}_{\mathrm{v}}$ channel $\alpha$-subunits may reflect differences in the interactions among $\mathrm{Na}_{\mathrm{v}} \beta$ subunits. Among the $\mathrm{Na}_{\mathrm{v}} \beta$ subunits, only $\mathrm{Na}_{\mathrm{v}} \beta 4$ has a PDZ binding motif like Kv1 channel $\alpha$ subunits. $\mathrm{Na}_{\mathrm{v}} \beta 4$ is thought to interact with $\mathrm{Na}_{\mathrm{v}} 1.6$ and be responsible for "open-channel block" of $\mathrm{Na}_{\mathrm{v}}$ channels, permitting highfrequency firing in neurons (Grieco et al., 2005). We speculate that PSD-93 may be localized through interactions with $\mathrm{Na}_{\mathrm{v}} \beta 4$, spatially and molecularly coupling $\mathrm{Na}_{\mathrm{v}} 1.6$ and Kv1 channels at the AIS. Alternatively, PSD-93 may modulate the ability of $\mathrm{Na}_{\mathrm{v}} \beta 4$ to mediate open-channel block by binding to the $\mathrm{C}$ terminus of $\mathrm{Na}_{\mathrm{v}} \beta 4$.

A multistep sequence of events for AIS clustering of $\mathrm{Na}_{\mathrm{v}}$ channels has been proposed (Fache et al., 2004). Both endocytic elimination from somatodendritic domains and directed sorting of channels to axons are thought to contribute to their localization 


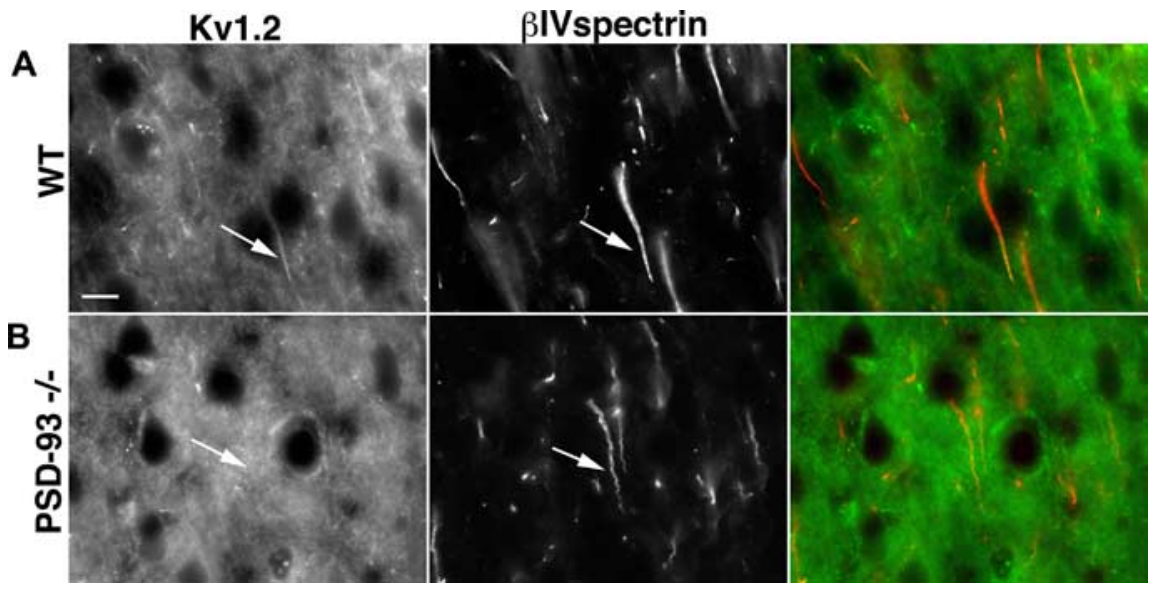

Figure 7. Kv1 channels are not clustered at the AIS of P10 cortical neurons in PSD-93 - / - mice. A, Kv1.2 (green) colocalizes with AIS $\beta$ IV spectrin (red) immunostaining (arrows) in P10 WT mouse cortex. B, Kv1.2 (green) is not enriched at $\beta$ IV spectrinlabeled AIS (arrow) in P10 PSD-93-/- mice. Scale bar, $10 \mu \mathrm{m}$.
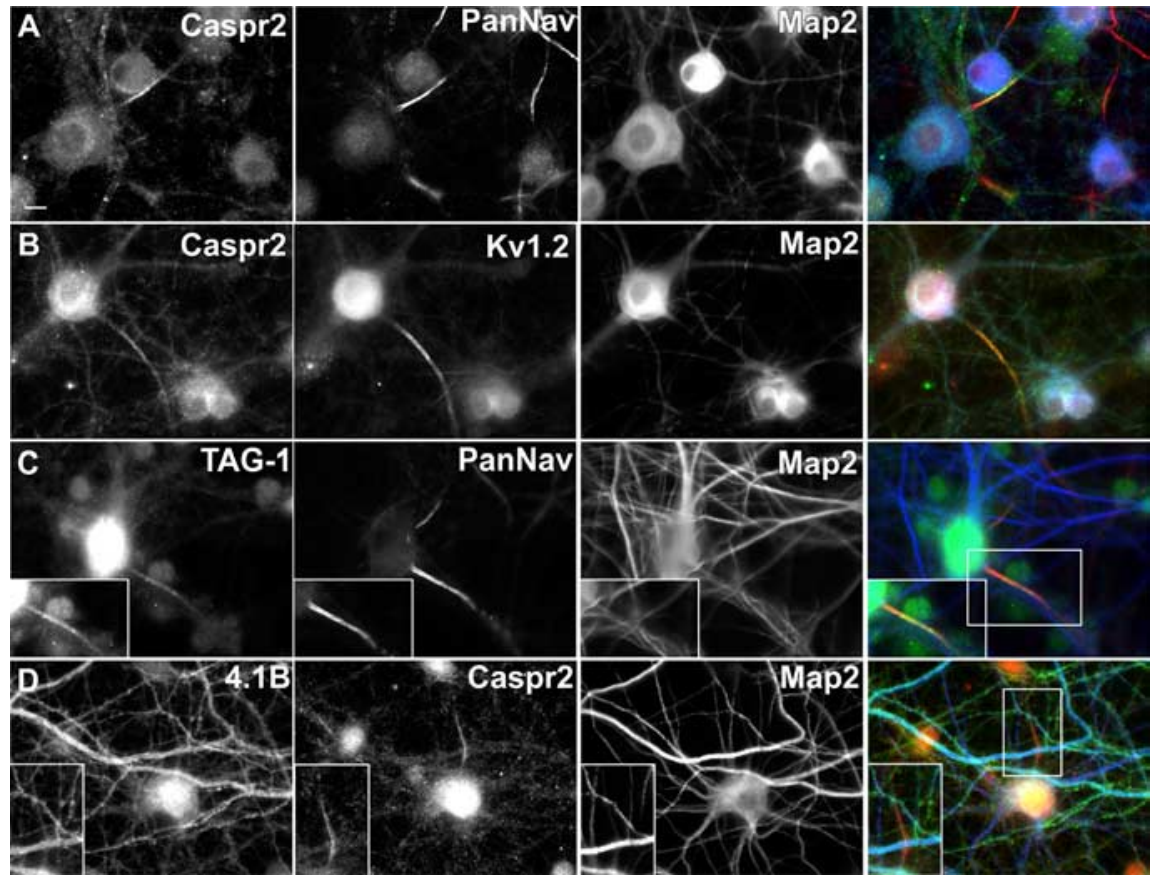

Figure 8. Caspr2 and TAG-1 are located at the AIS of cultured hippocampal neurons. $A$, Caspr2 immunostaining (green) colocalizes with Pan-Na immunoreactivity (red) at the AIS. B, Caspr2 (green) and Kv1.2 (red) colocalize in cultured hippocampal neurons. C, TAG-1 (green) and Pan- $\mathrm{Na}_{\mathrm{v}}$ (red) immunoreactivity colocalize at the AIS of cultured hippocampal neurons. Inset, AIS with increased brightness in the TAG-1 channel. D, Protein 4.1B (green) does not colocalize with Caspr2 (red) at the AlS of cultured hippocampal neurons. Somatodendritic domains are defined by MAP2 staining (blue). Scale bar, $10 \mu \mathrm{m}$.

(Garrido et al., 2001; Fache et al., 2004). Subsequently, $\mathrm{Na}_{\mathrm{v}}$ channels are selectively retained at the AIS through interactions with ankG. Recently, Gu et al. (2006) reported that axonal trafficking of Kv1 channels depends on interactions between accessory $\mathrm{Kv} \beta 2$ subunits, a microtubule plus-end tracking protein called EB1, and the microtubule-based motor KIF3/kinesin II. Similarly, Rivera et al. (2007) provided evidence that KIF5B interacts with Kv1 channels and contributes to their axonal localization. Therefore, as for $\mathrm{Na}_{\mathrm{v}}$ channels, it is likely that the AIS clustering of Kv1 channels is a multistep sequence of events, including directed trafficking to the axon followed by retention of channels at the AIS by PSD-93. Although we have focused on their AIS localization, Kv1 channels can also be detected along unmyelinated ax- ons and in somatodendritic domains depending on the neuron (Trimmer and Rhodes, 2004; Khavandgar et al., 2005). Therefore, additional mechanisms regulating Kv1 channel localization in neurons remain to be identified.

In conclusion, PSD-93 functions not only at synapses, but also as a scaffold, independent of Caspr2, to cluster and restrict Kv1 channels at the AIS. These results support the idea that scaffolding proteins, rather than CAMs, direct the assembly of ion channel complexes at the AIS. Therefore, although many protein components may be common to the AIS and juxtaparanodes, the mechanisms that mediate their assembly are distinct. Like nodes of Ranvier, the juxtaparanodes are organized from the "outside-in," but the AIS is assembled from the "inside-out" (Dzhashiashvili et al., 2007; Hedstrom et al., 2007; Yang et al., 2007).

\section{References}

Bekele-Arcuri Z, Matos MF, Manganas L, Strassle BW, Monaghan MM, Rhodes KJ, Trimmer JS (1996) Generation and characterization of subtype-specific monoclonal antibodies to $\mathrm{K}+$ channel alpha- and beta-subunit polypeptides. Neuropharmacology 35:851-865.

Berghs S, Aggujaro D, Dirkx R, Maksimova E, Stabach P, Hermel JM, Zhang JP, Philbrick W, Slepnev V, Ort T, Solimena M (2000) betaIV spectrin, a new spectrin localized at axon initial segments and nodes of ranvier in the central and peripheral nervous system. J Cell Biol 151:985-1002.

Boiko T, Van Wart A, Caldwell JH, Levinson SR, Trimmer JS, Matthews G (2003) Functional specialization of the axon initial segment by isoform-specific sodium channel targeting. J Neurosci 23:2306-2313.

Davey F, Hill M, Falk J, Sans N, Gunn-Moore FJ (2005) Synapse associated protein 102 is a novel binding partner to the cytoplasmic terminus of neurone-glial related cell adhesion molecule. J Neurochem 94:1243-1253.

Denisenko-Nehrbass N, Oguievetskaia K, Goutebroze L, Galvez T, Yamakawa H, Ohara O, Carnaud M, Girault JA (2003) Protein 4.1B associates with both Caspr/paranodin and Caspr2 at paranodes and juxtaparanodes of myelinated fibres. Eur J Neurosci 17:411-416.

Devaux JJ, Kleopa KA, Cooper EC, Scherer SS (2004) KCNQ2 is a nodal $\mathrm{K}^{+}$channel. J Neu-

rosci 24:1236-1244.

Dodson PD, Barker MC, Forsythe ID (2002) Two heteromeric Kv1 potassium channels differentially regulate action potential firing. J Neurosci 22:6953-6961.

Dzhashiashvili Y, Zhang Y, Galinska J, Lam I, Grumet M, Salzer JL (2007) Nodes of Ranvier and axon initial segments are ankyrin G-dependent domains that assemble by distinct mechanisms. J Cell Biol 177:857-870.

Elias GM, Funke L, Stein V, Grant SG, Bredt DS, Nicoll RA (2006) Synapsespecific and developmentally regulated targeting of AMPA receptors by a family of MAGUK scaffolding proteins. Neuron 52:307-320.

Eshed Y, Feinberg K, Poliak S, Sabanay H, Sarig-Nadir O, Spiegel I, Bermingham Jr JR, Peles E (2005) Gliomedin mediates schwann cell-axon interaction and the molecular assembly of the nodes of ranvier. Neuron 47:215-229. 
Fache MP, Moussif A, Fernandes F, Giraud P, Garrido JJ, Dargent B (2004) Endocytotic elimination and domain-selective tethering constitute a potential mechanism of protein segregation at the axonal initial segment. J Cell Biol 166:571-578.

Fukaya M, Watanabe M (2000) Improved immunohistochemical detection of postsynaptically located PSD-95/SAP90 protein family by protease section pretreatment: a study in the adult mouse brain. J Comp Neurol 426:572-586.

Garrido JJ, Fernandes F, Giraud P, Mouret I, Pasqualini E, Fache MP, Jullien F, Dargent B (2001) Identification of an axonal determinant in the C-terminus of the sodium channel $\mathrm{Na}(\mathrm{v})$ 1.2. EMBO J 20:5950-5961.

Garrido JJ, Giraud P, Carlier E, Fernandes F, Moussif A, Fache MP, Debanne D, Dargent B (2003) A targeting motif involved in sodium channel clustering at the axonal initial segment. Science 300:2091-2094.

Gollan L, Sabanay H, Poliak S, Berglund EO, Ranscht B, Peles E (2002) Retention of a cell adhesion complex at the paranodal junction requires the cytoplasmic region of Caspr. J Cell Biol 157:1247-1256.

Grieco TM, Malhotra JD, Chen C, Isom LL, Raman IM (2005) Openchannel block by the cytoplasmic tail of sodium channel beta4 as a mechanism for resurgent sodium current. Neuron 45:233-244.

Grosse G, Draguhn A, Hohne L, Tapp R, Veh RW, Ahnert-Hilger G (2000) Expression of Kv1 potassium channels in mouse hippocampal primary cultures: development and activity-dependent regulation. J Neurosci 20:1869-1882.

Gu C, Jan YN, Jan LY (2003) A conserved domain in axonal targeting of Kv1 (Shaker) voltage-gated potassium channels. Science 301:646-649.

Gu C, Zhou W, Puthenveedu MA, Xu M, Jan YN, Jan LY (2006) The microtubule plus-end tracking protein $\mathrm{EB} 1$ is required for $\mathrm{Kvl}$ voltage-gated $\mathrm{K}+$ channel axonal targeting. Neuron 52:803-816.

Hedstrom KL, Rasband MN (2006) Intrinsic and extrinsic determinants of ion channel localization in neurons. J Neurochem 98:1345-1352.

Hedstrom KL, Xu X, Ogawa Y, Frischknecht R, Seidenbecher CI, Shrager P, Rasband MN (2007) Neurofascin assembles a specialized extracellular matrix at the axon initial segment. J Cell Biol 178:875-886.

Inda MC, Defelipe J, Munoz A (2006) Voltage-gated ion channels in the axon initial segment of human cortical pyramidal cells and their relationship with chandelier cells. Proc Natl Acad Sci USA 103:2920-2925.

Jentsch TJ (2000) Neuronal KCNQ potassium channels: physiology and role in disease. Nat Rev Neurosci 1:21-30.

Khaliq ZM, Raman IM (2006) Relative contributions of axonal and somatic $\mathrm{Na}$ channels to action potential initiation in cerebellar Purkinje neurons. J Neurosci 26:1935-1944.

Khavandgar S, Walter JT, Sageser K, Khodakhah K (2005) Kv1 channels selectively prevent dendritic hyperexcitability in rat Purkinje cells. J Physiol (Lond) 569:545-557.

Kim E, Sheng M (1996) Differential K+ channel clustering activity of PSD-95 and SAP97, two related membrane-associated putative guanylate kinases. Neuropharmacology 35:993-1000.

Kim E, Niethammer M, Rothschild A, Jan YN, Sheng M (1995) Clustering of Shaker-type $\mathrm{K}+$ channels by interaction with a family of membraneassociated guanylate kinases. Nature 378:85-88.

Kim E, Cho KO, Rothschild A, Sheng M (1996) Heteromultimerization and NMDA receptor-clustering activity of Chapsyn-110, a member of the PSD-95 family of proteins. Neuron 17:103-113.

Kole MHP, Letzkus JJ, Stuart GJ (2007) Axon initial segment Kv1 channels control axonal action potential waveform and synaptic efficacy. Neuron 55:633-647.

Komada M, Soriano P (2002) [Beta]IV-spectrin regulates sodium channel clustering through ankyrin-G at axon initial segments and nodes of Ranvier. J Cell Biol 156:337-348.

Kuba H, Ishii TM, Ohmori H (2006) Axonal site of spike initiation enhances auditory coincidence detection. Nature 444:1069-1072.

Lai HC, Jan LY (2006) The distribution and targeting of neuronal voltagegated ion channels. Nat Rev Neurosci 7:548-562.
Laube G, Roper J, Pitt JC, Sewing S, Kistner U, Garner CC, Pongs O, Veh RW (1996) Ultrastructural localization of Shaker-related potassium channel subunits and synapse-associated protein 90 to septate-like junctions in rat cerebellar Pinceaux. Brain Res Mol Brain Res 42:51-61.

Lemaillet G, Walker B, Lambert S (2003) Identification of a conserved ankyrin-binding motif in the family of sodium channel alpha subunits J Biol Chem 278:27333-27339.

Majoie HJ, de Baets M, Renier W, Lang B, Vincent A (2006) Antibodies to voltage-gated potassium and calcium channels in epilepsy. Epilepsy Res 71:135-141

Manganas LN, Trimmer JS (2000) Subunit composition determines Kv1 potassium channel surface expression. J Biol Chem 275:29685-29693.

Manganas LN, Akhtar S, Antonucci DE, Campomanes CR, Dolly JO, Trimmer JS (2001) Episodic ataxia type-1 mutations in the Kv1.1 potassium channel display distinct folding and intracellular trafficking properties. J Biol Chem 276:49427-49434

McEwen DP, Isom LL (2004) Heterophilic interactions of sodium channel betal subunits with axonal and glial cell adhesion molecules. J Biol Chem 279:52744-52752.

McGee AW, Topinka JR, Hashimoto K, Petralia RS, Kakizawa S, Kauer FW Aguilera-Moreno A, Wenthold RJ, Kano M, Bredt DS (2001) PSD-93 knock-out mice reveal that neuronal MAGUKs are not required for development or function of parallel fiber synapses in cerebellum. J Neurosci 21:3085-3091.

Nakahira K, Shi G, Rhodes KJ, Trimmer JS (1996) Selective interaction of voltage-gated $\mathrm{K}+$ channel beta-subunits with alpha-subunits. J Biol Chem 271:7084-7089.

Ogiwara I, Miyamoto H, Morita N, Atapour N, Mazaki E, Inoue I, Takeuchi T, Itohara S, Yanagawa Y, Obata K, Furuichi T, Hensch TK, Yamakawa K (2007) $\mathrm{Na}(\mathrm{v}) 1.1$ localizes to axons of parvalbumin-positive inhibitory interneurons: a circuit basis for epileptic seizures in mice carrying an Scn1a gene mutation. J Neurosci 27:5903-5914.

Palmer LM, Stuart GJ (2006) Site of action potential initiation in layer 5 pyramidal neurons. J Neurosci 26:1854-1863.

Pan Z, Kao T, Horvath Z, Lemos J, Sul J-Y, Cranstoun SD, Bennett MV, Scherer SS, Cooper EC (2006) A common ankyrin-G-based mechanism retains KCNQ and $\mathrm{Na}_{\mathrm{v}}$ channels at electrically active domains of the axon. J Neurosci 26:2599-2613.

Poliak S, Peles E (2003) The local differentiation of myelinated axons at nodes of Ranvier. Nat Rev Neurosci 4:968-980.

Poliak S, Gollan L, Martinez R, Custer A, Einheber S, Salzer JL, Trimmer JS Shrager P, Peles E (1999) Caspr2, a new member of the neurexin superfamily, is localized at the juxtaparanodes of myelinated axons and associates with K+ channels. Neuron 24:1037-1047.

Poliak S, Gollan L, Salomon D, Berglund EO, Ohara R, Ranscht B, Peles E (2001) Localization of Caspr 2 in myelinated nerves depends on axon-glia interactions and the generation of barriers along the axon. J Neurosci 21:7568-7575

Poliak S, Salomon D, Elhanany H, Sabanay H, Kiernan B, Pevny L, Stewart CL, Xu X, Chiu SY, Shrager P, Furley AJ, Peles E (2003) Juxtaparanodal 
clustering of Shaker-like $\mathrm{K}+$ channels in myelinated axons depends on Caspr2 and TAG-1. J Cell Biol 162:1149-1160.

Rao A, Kim E, Sheng M, Craig AM (1998) Heterogeneity in the molecular composition of excitatory postsynaptic sites during development of hippocampal neurons in culture. J Neurosci 18:1217-1229.

Rasband MN (2004) It's "juxta" potassium channel. J Neurosci Res 76:749-757.

Rasband MN, Peles E, Trimmer JS, Levinson SR, Lux SE, Shrager P (1999) Dependence of nodal sodium channel clustering on paranodal axoglial contact in the developing CNS. J Neurosci 19:7516-7528.

Rasband MN, Park EW, Zhen D, Arbuckle MI, Poliak S, Peles E, Grant SGN, Trimmer JS (2002) Clustering of neuronal potassium channels is independent of their interaction with PSD-95. J Cell Biol 159:663-672.

Ratcliffe CF, Westenbroek RE, Curtis R, Catterall WA (2001) Sodium channel beta1 and beta3 subunits associate with neurofascin through their extracellular immunoglobulin-like domain. J Cell Biol 154:427-434.

Rhodes KJ, Keilbaugh SA, Barrezueta NX, Lopez KL, Trimmer JS (1995) Association and colocalization of $\mathrm{K}^{+}$channel $\alpha$ - and $\beta$-subunit polypeptides in rat brain. J Neurosci 15:5360-5371.

Rivera J, Chu PJ, Lewis Jr TL, Arnold DB (2007) The role of Kif5B in axonal localization of Kv1 K(+) channels. Eur J Neurosci 25:136-146.

Sheng M, Sala C (2001) PDZ domains and the organization of supramolecular complexes. Annu Rev Neurosci 24:1-29.

Sherman DL, Tait S, Melrose S, Johnson R, Zonta B, Court FA, Macklin WB, Meek S, Smith AJ, Cottrell DF, Brophy PJ (2005) Neurofascins are required to establish axonal domains for saltatory conduction. Neuron 48:737-742.
Shu Y, Duque A, Yu Y, Haider B, McCormick DA (2007) Properties of action potential initiation in neocortical pyramidal cells: evidence from whole cell axon recordings. J Neurophysiol 97:746-760.

Smart SL, Lopantsev V, Zhang CL, Robbins CA, Wang H, Chiu SY, Schwartzkroin PA, Messing A, Tempel BL (1998) Deletion of the K(V)1.1 potassium channel causes epilepsy in mice. Neuron 20:809-819.

Tiffany AM, Manganas LN, Kim E, Hsueh YP, Sheng M, Trimmer JS (2000) PSD-95 and SAP97 exhibit distinct mechanisms for regulating $\mathrm{K}(+)$ channel surface expression and clustering. J Cell Biol 148:147-158.

Traka M, Goutebroze L, Denisenko N, Bessa M, Nifli A, Havaki S, Iwakura Y, Fukamauchi F, Watanabe K, Soliven B, Girault JA, Karagogeos D (2003) Association of TAG-1 with Caspr2 is essential for the molecular organization of juxtaparanodal regions of myelinated fibers. J Cell Biol 162:1161-1172.

Trimmer JS, Rhodes KJ (2004) Localization of voltage-gated ion channels in mammalian brain. Annu Rev Physiol 66:477-519.

Van Wart A, Trimmer JS, Matthews G (2007) Polarized distribution of ion channels within microdomains of the axon initial segment. J Comp Neurol 500:339-352.

Yang Y, Ogawa Y, Hedstrom KL, Rasband MN (2007) Beta-IV spectrin is recruited to axon initial segments and nodes of Ranvier by ankyrinG. J Cell Biol 176:509-519.

Zhou D, Lambert S, Malen PL, Carpenter S, Boland LM, Bennett V (1998) AnkyrinG is required for clustering of voltage-gated Na channels at axon initial segments and for normal action potential firing. J Cell Biol 143: 1295-1304. 